\title{
Use of TRIZ, and TRIZ with Other Tools for Process Improvement: A Literature Review
}

\author{
Vladimír Sojka ${ }^{a}$, Petr Lepšík ${ }^{a^{*}}$ \\ ${ }^{a}$ Department of Machine Elements and Mechanisms, Technical University of Liberec, Liberec, Czech Republic
}

\begin{abstract}
Paper reviewing the use of TRIZ tools and methods in combination with other tools for better manufacturing and production processes improvement. A weakness of the current state of process improvement is mainly solving problems by trivial tools as Brainstorming, which leads to not ideal resolutions to problems in the process. This could be improved by the use of TRIZ. A literature review was used for examination of the current state and history of the use of TRIZ principles in a field of production processes. The review is chronologically structured and focuses on attempts to use TRIZ itself or in combination with other tools with a goal improvement of processes or activities related to the process. The research begins before the year 2000 and it ends by the year 2019. The use of TRIZ for process improvement was described by many authors, and many approaches were tried. From the results, it is seen that TRIZ methods should be beneficial for use in practice. Unfortunately, found solutions are either too complex or without specific descriptions. That could be a cause of why the implementation of TRIZ tools is not spread. Results of review lead to a need for a new, more user-friendly approach based on TRIZ principles for use by engineers in real practice.
\end{abstract}

Keywords:

TRIZ;

Process Improvement;

Lean Manufacturing;

Production Processes.

\section{Article History:}

$\begin{array}{llll}\text { Received: } & 21 & \text { June } & 2020 \\ \text { Accepted: } & 19 & \text { September } & 2020 \\ \text { Published: } & 01 & \text { October } & 2020\end{array}$

\section{1- Introduction}

If companies want to succeed and stay in the competition in the long run, they must make an effort to improve. The concept of continuous improvement is well known. The most common approaches for continuous process improvement are Lean thinking and Six Sigma. These approaches offer a good way to improve processes in companies. Its main strength is in the identification of problems, not in solving them. When problems are found, tools as brainstorming are used to solve these problems. Solutions generated by these tools could lead in a different direction from the ideal result. Or possibly, secondary problems could appear. There are more sophisticated methods for better and more innovative solutions. Innovative solutions can be found by the use of systematic creativity tools called TRIZ. TRIZ (Theory of Inventive Problem Solving) gives us an approach on how to solve problems within a way of evolution of a technical system. TRIZ principles and tools are based on previous research of thousands of patents where repeating patterns were discovered. There is a limited number of general problems and there is a limited number of solutions for these problems. These problems and their solutions are constantly repeating in time. Based on this knowledge, several tools and methods were made, which can help us to achieve a better solution to problems quickly. The use of TRIZ tools brings faster and more innovative solutions even for very difficult problems. Although TRIZ is originally designed for innovation of products, it should be a very good tool for improvement or innovation of processes.

This paper deals with the question of how TRIZ has been used for the improvement of production processes. How the TRIZ is used for improvement or innovation of the processes, or how is TRIZ used in combination with tools and methods used for the improvement of processes or activities related to processes.

\footnotetext{
* CoNTACT: Vladimir.sojka@tul.cz

DOI: http://dx.doi.org/10.28991/esj-2020-01234
}

(C) 2020 by the authors. Licensee ESJ, Italy. This is an open access article under the terms and conditions of the Creative Commons Attribution (CC-BY) license (https://creativecommons.org/licenses/by/4.0/). 
Several authors published review papers about the use of TRIZ tools in combination with other tools. Hua et al. [1] reviewing the use of TRIZ with other tools for a better design. A review of TRIZ for design is also presented by Coulibaly [2]. Rupani et al. [3] reviewing the use of TRIZ for services, the integration of TRIZ with other tools is reviewed by Lin et al. [4]. A review of the integration of TRIZ with Lean is described by Maia et al. [5]. None of these reviews deals with the use of TRIZ for process improvement in general. Maia et al. [5] deals with the integration of TRIZ with lean, but they are ignore other methods.

This paper aims to review the combination of TRIZ with other tools for the improvement of production processes, and looks into previous attempts to integrate TRIZ with other tools. Results could help with orientation in the field of use of TRIZ with other tools or as a starting point for other research of process improvement possibilities.

\section{2- Methods}

To answer the question of how was TRIZ used and how it is used as a way of improvement of processes or activities related to processes, a literature review was done. The main focus was on the use of sources from the Web of Science and Scopus databases. Because there have not been many publications on this topic other sources for research were included. Sources as Google Scholar, Researchgate, TRIZ Journal, etc. Found publications were investigated and conclusions were made. The process of the review is shown in Figure 1.

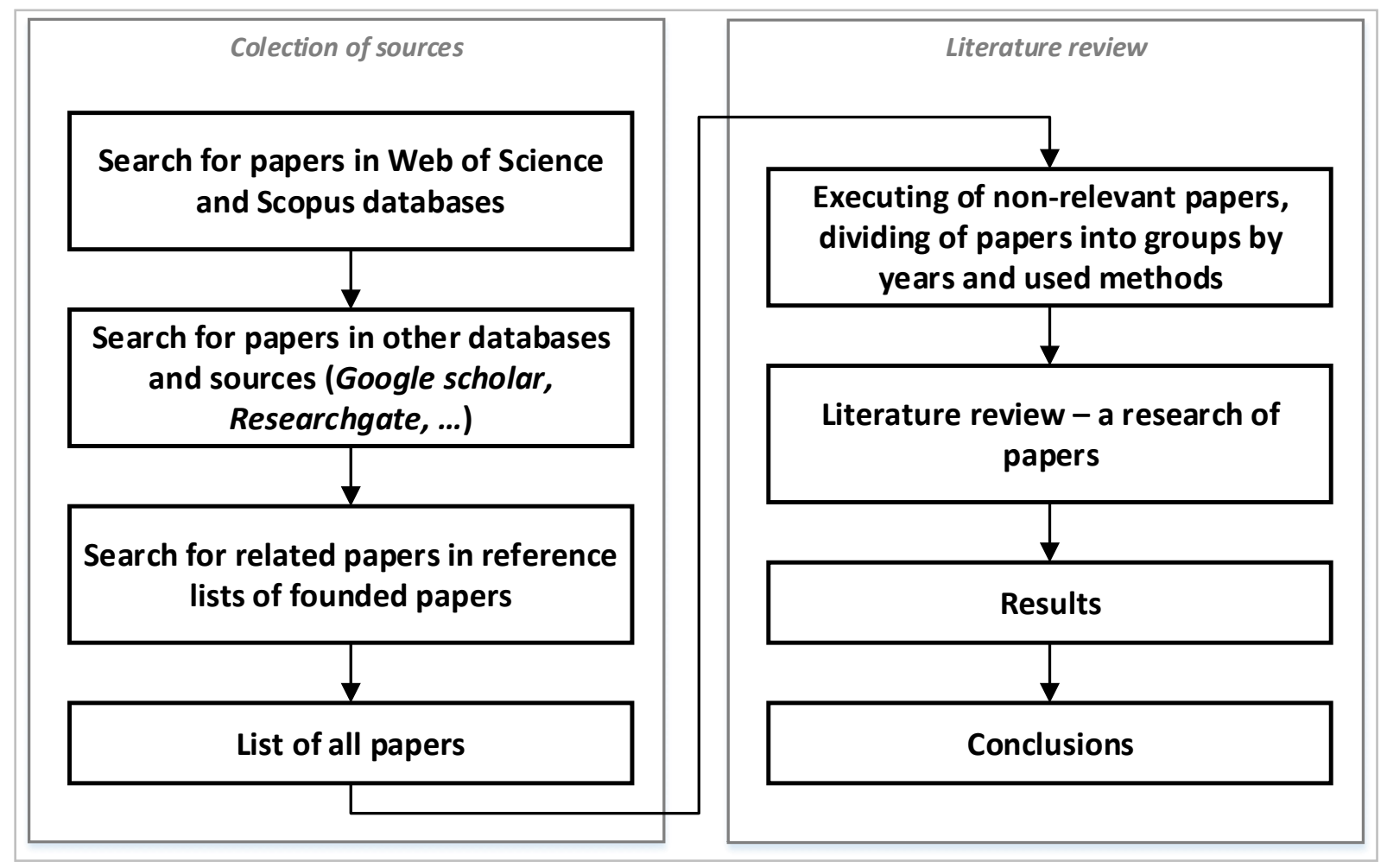

Figure 1. Flowchart of the literature review procedure.

\section{3- Literature Review}

The review is divided into chronological sections. In the first section, there are publications before the year 2000, the following sections are periods of five years in length. Research ended in 2019.

\section{3-1- Before the Year 2000}

In studies before 2000, TRIZ appears mainly used in the design of better products. The most used integration of TRIZ tools is with QFD (Quality Function Deployment), Taguchi method, and TOC (Theory of Constraints).

Domb [6] describes the integration of TRIZ with QFD when TRIZ tools are used to solve problems in the area of design of new products or processes. The integration of TRIZ and QFD is also described in other publications [7-10]. TRIZ, QFD, and Taguchi methods are combined by Terninko [9]. QFD is used to collect customers' requests, Taguchi brings approach for determination of parameters for robust design, and TRIZ is used for problem-solving. QFD and TRIZ are integrated by León-Rovira and Aguayo [7], where technical contradictions are defined in the roof of the QFD. Contradictions are then solved by TRIZ tools. Integration of TRIZ with QFD with the effort to find better solutions, and also for better technological future forecasting in a field of quality improvement is described by Domb [8]. Novick [10] wants to establish a Variability Reduction Plan and Pathway for the improvement of processes and 
quality. By combining tools like QFD, Taguchi, TOC, TRIZ, SPC (Statistical Process Control), or Kaizen. Because without a good plan, time, cost, or manpower can be used in the wrong place and at the wrong time.

Possible improvement of both, TOC and TRIZ methods is discussed by Rizzo [11]. As one of the usable tools, the 40 Inventive Principles can be used for resolving conflicts in Evaporating Cloud. On the other hand, Evaporating Cloud can help with the definition of contradictions for TRIZ solving The use of TOC's trees is described by Moura [12], where CRT (Current Reality Tree) and the CRD (Conflict Resolution Diagram) can help with the definition of micro problems and better formulation of technical and physical contradictions. A combination of Evaporating Cloud with TRIZ's 40 Inventive Principles is also described by Domb and Dettmer [13].

The use of TRIZ toolset to solve non-technical problems, and for solving problems connected to strategy and management is described by Domb and Dettmer [13] and by Domb [14]. Domb [14] described a three-step procedure for the improvement of Supply Chain Management. IFR (Ideal Final Result), Subject-Object-Action, and a list of resources are used for solving non-technical problems including services and processes by Belski [15]. Improvement of the process of new product design with the use of a combination of TRIZ with NLP (Neuro-Linguistic Programming) describes Becker and Domb [16]. Connection of the TRIZ and SAPB (Systematic Approach of Pahl and Beitz) with the same purpose but also for general problem-solving is described by Malmqvist et al. [17]. About recognition of the moment when focusing innovation on the product or on the process writes Cavallucci and Lutz [18]. TRIZ can be focused only on one system, product, or production system. Change of product requires changes in process, and when the process is innovated a new product can appear.

TRIZ tools were also used for practical problem-solving connected with the production or with the technology of manufacturing for example in a case study on the production of wine [19].

\section{3-2-Period from 2000 to 2004}

In 2000, more papers combining TRIZ with other methods and tools appeared. There were papers mainly about the use of TRIZ tools in a field of non-technical problems like services, strategy, and others, but there were also quite a lot of articles about integration with tools and methods based on brainstorming and similar methods, for example, psychological tools. As before 2000 there were still attempts to integrate QFD and TOC methods with TRIZ.

Not seen before was an integration of TRIZ with the design of eco products and processes or the use of TRIZ in a field of software development. Integration with tools for the design of products connected to manufacturing like DFMA or DFSS was also described. Most importantly for this research, there were first attempts to describe a positive effect of the use of TRIZ in the improvement of manufacturing processes with methodologies like Six Sigma and Lean.

Mann [20] describes the use of TRIZ for non-technical problems. He concludes that TRIZ can define or solve problems in business and other non-technical fields. Mann and Domb [21] write about the use of TRIZ to help companies to survive in E-business. Ruchti and Livotov [22] conclude that TRIZ can be very useful for better decision making in business fields. A new Contradiction matrix that is aiming at the application of TRIZ in business is described by Mann [23].

How to use the $5 \mathrm{~W} 1 \mathrm{H}$ tool with TRIZ methods is described by Apte et al. [24]. It can help with the formulation of problems, identification of parts in the system, finding IFR or all resources, or describe scientific effects. Other work from Care and Mann uses TRIZ with the MindMaps tool [25]. MindMap helps by grouping ideas and not to stop searching for the solution when the first good is found. Mann [26] describes how to use different types of thinking. Types of thinking from Six Hats could be combined with TRIZ for better solutions. Campbell [27] combines TRIZ and Brainstorming. Knowledge of TRIZ can help to fill a gap between general solution and desired specific one.

Hipple [28] tries to describe possible ways to bring the TRIZ in-to the organization as a replacement or as a combination with current creativity tools in the company. Tools and methods for combining with TRIZ are: Creative Problem Solving/brainstorming, Lateral Thinking, Six Hats, or social style instruments such as Myers Briggs 16 Types and many others.

The integration of TRIZ with the Taguchi method is also described by Apte and Man [29]. TRIZ generates ideas and Taguchi transforms them into reality. The comparison of TRIZ with NLP at the philosophical, methodological, and tool levels is described by Birdoux and Mann [30].

As before 2000, there are studies about the integration of TRIZ and TOC. Mann and Stratton integrate TRIZ with TOC. They discuss the connection between TRIZ and Evaporating Cloud [31], but they also focus on the relationship between TOC and TRIZ with manufacturing strategy development [32]. Both TOC and TRIZ are reducing costs, and improving Ideality and Value. 
TRIZ with QFD and Scenario Technique is described by Baessler et al. [33]. They use a seven stage process called W-Model. Chen and Liu [34] and [35] have combined the TRIZ, QFD, and Eco-innovation for products and processes with less environmental impact.

The next tools for integration with TRIZ, are design tools connected to manufacturing. De Feo and Bar-El [36] describe the integration of Ideation TRIZ (I-TRIZ) with DFSS. Almost the same is described by Bariani, Berti, and Lucchetta [37] where TRIZ is combined with DFMA. Even a more detailed description of integration is presented by Hur et al. [38].

Averboukh writes about the positive results of the use of TRIZ tools in Six Sigma's DMAIC or DFSS [39]. The use of TRIZ tools is most efficient at the Define and Improve phases. Averboukh also mentioned that there could be a problem with the training of users. Poppe and Gras described TRIZ for process improvement [40] They write about categories of process functions which are: Productive, Providing, Corrective, and Harmful. The other two categories are the result of unwanted but inevitable interactions and the result of implementation. The model of the process can be very complex and hard to make. Technology and processes innovations by TRIZ are also described by Winkless and Mann [41], where the TRIZ is used for improvement in a factory for food equipment.

Other ways of TRIZ to be used for process improvement is a combining it with process improvement tools. Lean, agile, and TOC tools with TRIZ are combined to improve a supply chain by Stratton and Warburton [42]. In 2004, Ikovenko and Bradley [43] write about similarities between Lean tools and TRIZ tools. They conclude that the Lean thinking application would be more sustainable when Lean tools are supported by TRIZ methods. A combination of TRIZ with 8D and MUDA is discussed by Campbell [44]. TRIZ can improve the 8D tool and it also could be used in combination with Lean for waste reduction.

The integration of Six Sigma and TRIZ is described by Kermani [45] or by Domb [46]. Kermani [45] writes that by the combination of Six Sigma and TRIZ a high degree of quality improvement can be achieved. He injected TRIZ tools into each step of the DMAIC cycle. Domb [46] writes that TRIZ with Six Sigma can be used to improve Transportation, IT product development, Education, Waste processing, or Warranty cost reduction.

There were also other applications of TRIZ connected to process improvement. Retseptor describes the use of 40 Inventive Principles for quality improvement [47]. A combination of ARIZ and NM method for better 5 levels problem-solving is discussed by Nakamura [48]. Petrali [49] combining TRIZ with other methods for product and process improvement. He combines many tools in one structured system. The system focuses on the improvement of all stages of production from the product model through the function model to the process model. He combines tools as QFD, FMEA, DFMA, Value analysis, Six Sigma, and TRIZ. TRIZ, in the field of software improvement is discussed by Stanbrook [50], and Rea [51].

\section{3-3-Period from 2005 to 2009}

In 2005, there were more studies about process improvement with TRIZ, a combination of TRIZ with Six Sigma methodology or with Lean. There are also many studies using TRIZ for non-technical problems like strategy and management. Another combination of TRIZ with tools and methods connected with process improvement also appeared.

The similarities between TPS (Toyota Production System) and TRIZ are discussed by Aggarwal [52]. The conclusion is that both of these methodologies are in many ways almost the same. Chemical processes are improved by the use of TRIZ by Robles et al. [53]. Duflou and D'hondt focus on systematic innovation in manufacturing processes [54]. Use of TRIZ for manufacturing processes improvement is also mentioned by Jin, San, and Li [55], where authors write about the beneficial use of TRIZ in many fields connected to manufacturing as software, management, products, management, and technology development. IFR and Patterns of Evolution are used for process improvement by Fresner and Jantschgi [56]. Domb and Kling describe the use of TRIZ for cost-related problems in processes [57]. Bligh [58] describes an overlap between Lean a TRIZ methodologies. TRIZ and Lean have many common points. Both trying to improve the system, both trying to make the current state better. The goal of Lean is to eliminate or reduce waste, TRIZ is trying to use all resources and use them in a different way. TRIZ can be also used as a Lean tool for more challenging problems. Li et al. use TOC for contradiction definition, then solve problems by TRIZ [59].

Kumar [60] uses a combination of TRIZ and Six Sigma for software process improvement. 40 contradiction matrix is used for solving of problems found by Six Sigma. Zhao integrates TRIZ with Six Sigma for the improvement of services and processes [61]. He uses TRIZ tools in every step of the DMAIC improvement cycle. Averboukh [62] and [63] comes up with TRIZ - Six Sigma methods. Averboukh systematically integrated TRIZ tools into Six Sigma roadmap. Averboukh describes how to use this new method for analysis and elimination of root causes [62], she also uses this method for cost reduction [63]. Filmore suggests that TRIZ has a more focused toolset for creative solving than Lean/Six Sigma [64]. The integration of TRIZ with Six Sigma is also considered by Šibalija and Majstorovic [65]. They conclude that the integration of TRIZ and Six Sigma is beneficial. TRIZ toolset with the DMAIC cycle is 
combined by Xie and Li [66]. Brad et al. come up with TRIZ/Six Sigma algorithm for process improvement [67]. Where they combine TRIZ with DMAIC.

Better customers' satisfaction and also improved quality are achieved by Chen, Hsu, and Chang [68] by a combination of TRIZ with the Kano model. Kaizen, Poka-Yoke, and TRIZ are combined to get better quality and higher safety of processes by Van Scyoc [69]. Improvement of agile manufacturing with TRIZ is discussed by Hetherington and Ismail [70]. Movarrei and Vessal write about the improvement of Supply Chain Management by the use of Inventive principles [71]. Rau and Fang [72] use QFD and TRIZ for improvement in logistics. Another use of QFD with TRIZ by Su and Lin [73] focuses on the improvement of services in electronic commerce. QFD, FMEA, and TRIZ are also used in a similar way by Wang et al. [74]. Improvement of the manufacturing processes and its strategy by the use of contradiction from TRIZ and TOC is discussed by Shahbazpour and Seidel [75].

Between 2005 and 2009 there were many studies about how to use TRIZ tools to solve non-technical problems, like defining strategy, improvement of management, and others.

TRIZ for a business project is used by Prim and Trabasso [76], the main use is in project preparation by the development of requirements and goals. The training process is improved by the use of Function analysis and new process maps by $\mathrm{Ru}$ and $\mathrm{Ru}$ [77]. Smith shows the improvement of business processes from process maps [78]. Souchkov [79] deals with the improvement of management and business systems. S-curves for the identification of a current state of the processes are used by Sui et al. [80], results were used to make relevant strategic decisions. TRIZ for business process re-engineering is shown by Rau and Fang [72]. Sui et al. [80] describe a strategy for Organization Learning with TRIZ. Hipple [81] and [82] describes the combination of TRIZ with other tools. The author writes that when a company tries to use TRIZ, it should combine it with other established tools. TRIZ can be used under the umbrella of a different method. Multi-level problem solving, which uses five levels to solve the problem is described by Frenklach [83]. Non-typical problems are solved by the use of TRIZ and OTSM (General Theory of Thinking) by Khomenko and Ashtiani [84]. A similar topic is also described by Cavallucci and Khomenko [85]. Other studies integrate TRIZ with others, for example, integration of the DFMA [86], or combining with SAPB [87].

\section{3-4-Period from 2010 to 2014}

In 2010, there were lots of studies in the use of TRIZ tools and methods for process improvement or at least the use of TRIZ in connection with manufacturing processes. There were still attempts to combine TRIZ with TOC or QFD. Many studies on the combination of TRIZ with Six Sigma or Lean appeared. A number of ecologically aimed studies were growing.

TRIZ is used for the enhancement of manufacturing processes in many studies. For example, Chan et al. [88] deal with the improvement of the manufacturing process for lower environmental impact. Similarities between TRIZ, TOC, and Lean are described by Martin [89], and the use of TRIZ with these tools is recommended. Lean, TOC, and TRIZ are also described by Anosike and Lim [90]. They use Lean and TRIZ in the TOC framework, TOC, and TRIZ in the Lean framework and TOC and Lean in the TRIZ framework. The idea was to take the benefits of each method. TOC brings focus and logical thinking, Lean is good for waste elimination and TRIZ enables creativity and foresight. Later they came up with an obvious parallel between TRIZ, TOC, and Lean in three equations.

$$
\begin{aligned}
& \text { Ideality }=\frac{\text { Benefits }}{(\text { Harms }+ \text { Costs })} \\
& \text { Goal }=\frac{\text { Throughput }}{(\text { Inventory }+ \text { Operating Expenses })} \\
& \text { Lean }=\frac{\text { Value }}{(\text { Waste }+ \text { Costs })}
\end{aligned}
$$

Equation 1 is the main equation for TRIZ ideality. Equation (2) is the equation from TOC. Equation (3) could be the equation for Lean [91].

Navas and Machado [92] describe the use of TRIZ and Lean for Product Lifecycle Management (PLM) where they are trying to find the best way to deal with the old stages of technical systems. 40 Inventive principles and a Contradiction matrix for better process capacity, safety, and ecology are used by Wang and Hsiung [93]. A better approach to ecology is also described by Bashikite and Karaulova [94], where green lean with TRIZ are integrated. The improvement of a whole manufacturing organization is discussed by Li et al. [95]. Similarly, Lanke and Ghodrati [96], who focus on the use of TRIZ for small improvements and innovations at the start of production of a new product. Moreira [97] discusses the improvement in assembly manufacturing with the use of Lean, direct observation, and tools of TRIZ. Muruganantham et al. [98] describe another approach to the integration of TRIZ with Lean 
manufacturing, where Lean is used to find and narrow down problems, then these problems are solved by the use of TRIZ with better results.

Technological improvements in manufacturing are described by Hsia et al. [99] or Sheu and Hou [100]. Sheu and Hou using Device Trimming methodology to improve manufacturing technology by the redesign of the machine [100], and redesign of processing machine [101]. Safety improvement in technology processes is presented by Hsia and Huang [102], where Substance-Field Analysis and contradiction analysis are used to lower hazard potential and improve factory safety. Systematic innovation in Lean manufacturing is described by Navas and Machado [103]. They review the possibilities of TRIZ use with Lean. Sousa, Navas, and Machado [104] write about the use of Lean and TRIZ methods for better maintenance. They try to applicate TRIZ with tools like 5S, Kaizen, PDCA, TPM, Autonomous Maintenance, or VSM. Waste elimination with the use of TRIZ toolset is described by Thurnes et al. [105], where necessary waste is eliminated. Necessary waste is in its basic contradiction that is why TRIZ could help to eliminate these types of activities in the process. Thurnes also describes a list of examples for the use of 40 Inventive principles in Lean manufacturing [106]. TRIZ for Lean manufacturing is also used by Muruganantham et al. [107]. Improvement of Value Stream Mapping by TRIZ is described by Cabera and Li [108], the combination leads to better performance and production. The use of TRIZ for Lean Supply Chain Management is presented by Navas and Machado [109]. Moussa and others show that TRIZ can be used for Product or process design with environmental impact [110]. 5S with TRIZ is used Dewi et al. [111]. TRIZ tools are used in 5S methodology to solve problems that occurred. SMED and other Lean tools are improved by TRIZ by Kumaresanand Saman [112].

In 2010, integration of Six Sigma and TRIZ is more and more described. Attempt to integrate TRIZ with Six Sigma in the form of an algorithm called Sigma-TRIZ is described by Brad [113]. The author itself mentioned that this algorithm could be difficult to use, because of the TRIZ complexity. TRIZ tools are implemented into the DMAIC cycle, which is described by Soti et al. [114]. DMAIC and TRIZ are also combined by Zhao and Zhao [115]. Lean/Six Sigma on banking services is applied by Wang and Chen [116]. They used the Contradiction Matrix and 40 Inventive principles to improve process performance. Annamalai et al. [117], also combine TRIZ and Lean/Six Sigma. TRIZ tools and methods were implemented into DMAIC.

Quality improvement with the help of TRIZ is described by Yang et al. [118] and Guo, Sun, and Xu [119]. 40 Inventive principles with other tools are used for quality improvement by Wirawan and Ayu [120]. SERVQUAL (Service quality) measurement, Kano model, or FMEA are combined with the TRIZ toolset in the service industry to achieve better service quality. Services are also improved by TRIZ by Kim and Yoon [121] or Regazzoni et al. [122]. Both use the TRIZ toolset for the improvement of products and services. Cascini uses TRIZ for technology forecasting [123].

A combination of QFD and TRIZ is still described by several authors. Wang and Chang [124] use QFD, FMEA, and TRIZ for product design. Minglang with Jianghua and Huang [125] combine QFD, TRIZ, and DOE to reach the same goal. The use of the QFD/TRIZ combination to resolve problems in the QFD prioritization algorithm is described by Tseng, Torng, and Lin [126]. A combination of TRIZ and QFD for energy-saving products present Zheng, Zhang, and Zhang [127]. Innovations in the medical field by IFR from TRIZ and QFD methods are described by Hu and Yeh [128]. The Taguchi method is used with the contradiction matrix for the optimization of process parameters by Jou et al. [129].

The next variety of TRIZ use is for solving non-technical problems. Lee and Leu use of TRIZ with VE (Value Engineering) to improve business processes [130]. Jiannan and Dongmei focus on strategic decisions for the new product's forecasting [131], where the decisions are based on technology forecasting by the evolution of the system. Lebepe with Emwanu comparing the solution of non-technical problems with TRIZ and TOC [132]. TRIZ has many strengths, but there are weaknesses too, it takes longer to learn it, quite difficult to use it. Brainstorming and TRIZ are compared by Hass et al. [133], where the experimental proof of creative value of TRIZ is shown. The experiment shows that with TRIZ used in brainstorming season, there can be more and more innovative ideas generated in a shorter time than by classical brainstorming. Selected TRIZ tools for problem-solving at the shop floor level are presented by Jirman and Mašín in [134]. Project management improvement is discussed by Ioi et al. [135]. Petrović et al. discuss how TRIZ helps to enhance process planning [136]. Eco-innovation in chemical processes is applied by Ferrer et al. [137]. Training of TRIZ is discussed by Azlan, Ariz, and Yusof [138] and they conclude, that it is not an easy process.

\section{3-5-Period from 2015 to 2019}

After 2014 the overall number of papers about the combination of TRIZ tools with other techniques for process improvement is less than between 2010 and 2014.

Brad et al. [139] use TRIZ for process improvement in the form of a twelve-step algorithm. Nine-step technological process optimization by Trimming is described by Li et al. [140]. Maia, Alves, and Leão [5] discuss the relationship 
between TRIZ tools with Lean principles, the methodology for improvement in the textile and clothing industry is also presented. Toyota Kata with TRIZ for sustaining innovation is described by Toivonen [141]. Patent research, Functional analysis, Trimming Engineering parameters, and Contradiction matrix were reviewed for problem-solving related to manufacturing, reliability, and production systems design by Arcidiacono and Bucciarelli [142]. A Substance-Field Analysis and Contradiction Matrix were used for the solution of the ergonomic problems in the workshop by Alves et al. [143]. How TRIZ can help with the development of Lean PSS (Product-Service System) management is described by Pacheco et al. [144]. Improvement of the turning process for better parameters of final parts is described by Ghani et al. [145]. TRIZ is also used for a longer lasting of equipment [146]. A new and better design of machine tools is described by Hsieh et al. [147]. Improvement of VSM by TRIZ is shown by Toivonen and Siitinen [148]. Su and Su use TRIZ for the improvement of the manufacturing of color filters [149]. Chemical processes are improved by Livotov et al. [150] or by Pokhrel et al. [151].

The combination of Six Sigma and TRIZ was after 2014 discussed by Jiang and Nguyen [152] or Lin et al. [153]. Lin et al. combine Six Sigma, Taguchi, and TRIZ for improvement of the coffee roasting process [153], while Jiang and Nguyen [152] use Lean/Six Sigma with TRIZ for improvement of quality, productivity, effectiveness, elimination of waste, and other.

There are many other uses of TRIZ between 2015 and 2019. TRIZ added into SWOT analysis [154]. A better problem-solving method is described by Harlim and Belski [155]. Or a combination of TRIZ with Pugh's Matrix by Karnjanasomwong and Thawesaengskulthai [156]. Improvement of services is describing Lee, Leu, and Huang [157] by the use of FMEA, Lean, TRIZ, and Six Sigma. Lee, Chen, and Trappey [158] focus on the enhancement of customer satisfaction. Another use of TRIZ is for ex-ample for non-technical problems [159]. NLP and TRIZ are reviewed by Chrząszcz [160]. Swee trying to improve quality in the food industry by TRIZ toolset [161]. Brainstorming, Morphological Analysis, and TRIZ are combined for a generation of better ideas by Shealy et al. [162]. Project management improved by the use of ARIZ is described by Navas et al. [163].

\section{4- Results}

First publications aiming at the use of TRIZ in combination with other tools appeared in the year 1996. After the year 2000, the number of publications grown. In recent years, the number of publications with this topic decrease. Numbers of publications in time can be seen in Figure 2.

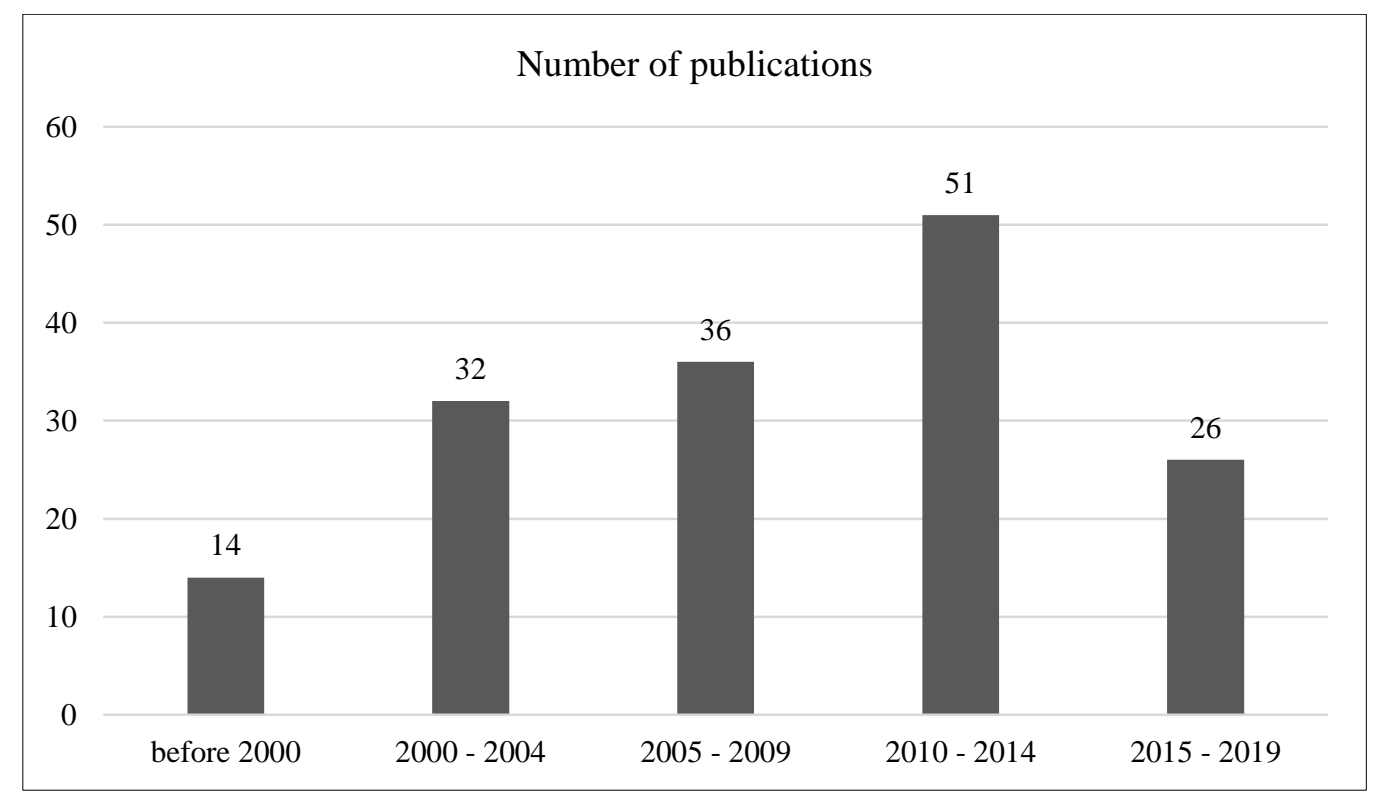

Figure 2. Numbers of publications in years

From the year 1996 until 2019 most of the reviewed publications aimed at the integration of TRIZ with lean principles and process improvement in general. Secondly, there is a high number of publications about the application of TRIZ itself or in combination with other tools for non-technical problems which can be business problems, problems in management, and others. These topics are partially related to processes. Numbers of publication and its aim is visualized in Figure 3. 


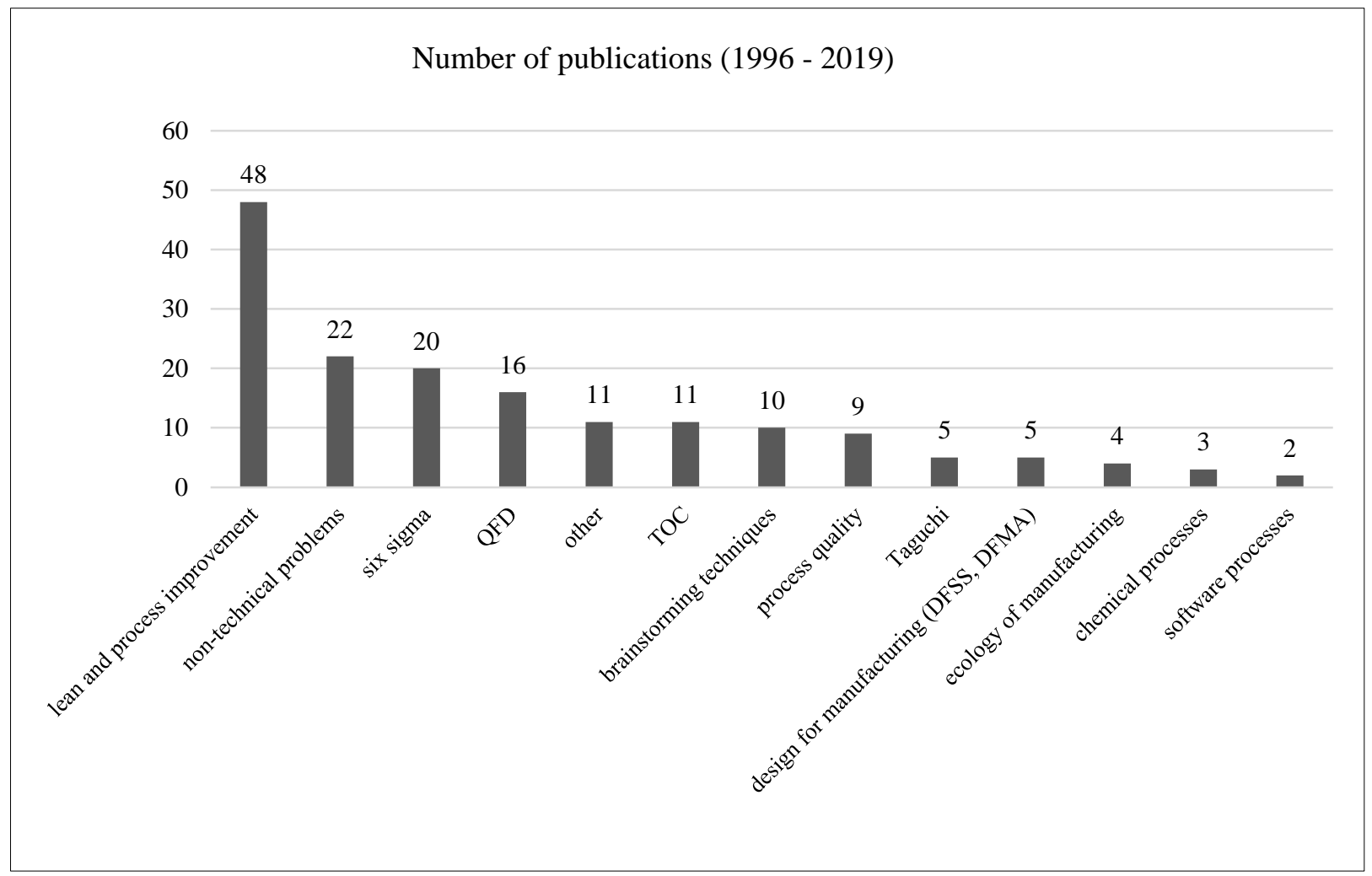

Figure 3. Aim of publications.

For better understanding, publications can be divided into three groups. First, publications focusing on the use of TRIZ for process improvement, which can be papers about the integration of TRIZ with lean thinking, six sigma, quality of processes, the ecology of processes, chemical, and software processes. The second group are publications focusing on the use of TRIZ for improvement of Design activities related to processes, which can be the design for six sigma, design for manufacturing and assembly, QFD, Taguchi method, and TOC. The third group are papers aiming at the use of TRIZ for problem-solving in general. In this group there are papers about the use of TRIZ with brainstorming techniques, solving non-technical problems, and others, like neuro-linguistic programming. The number of papers in these groups is shown in Figure 4.

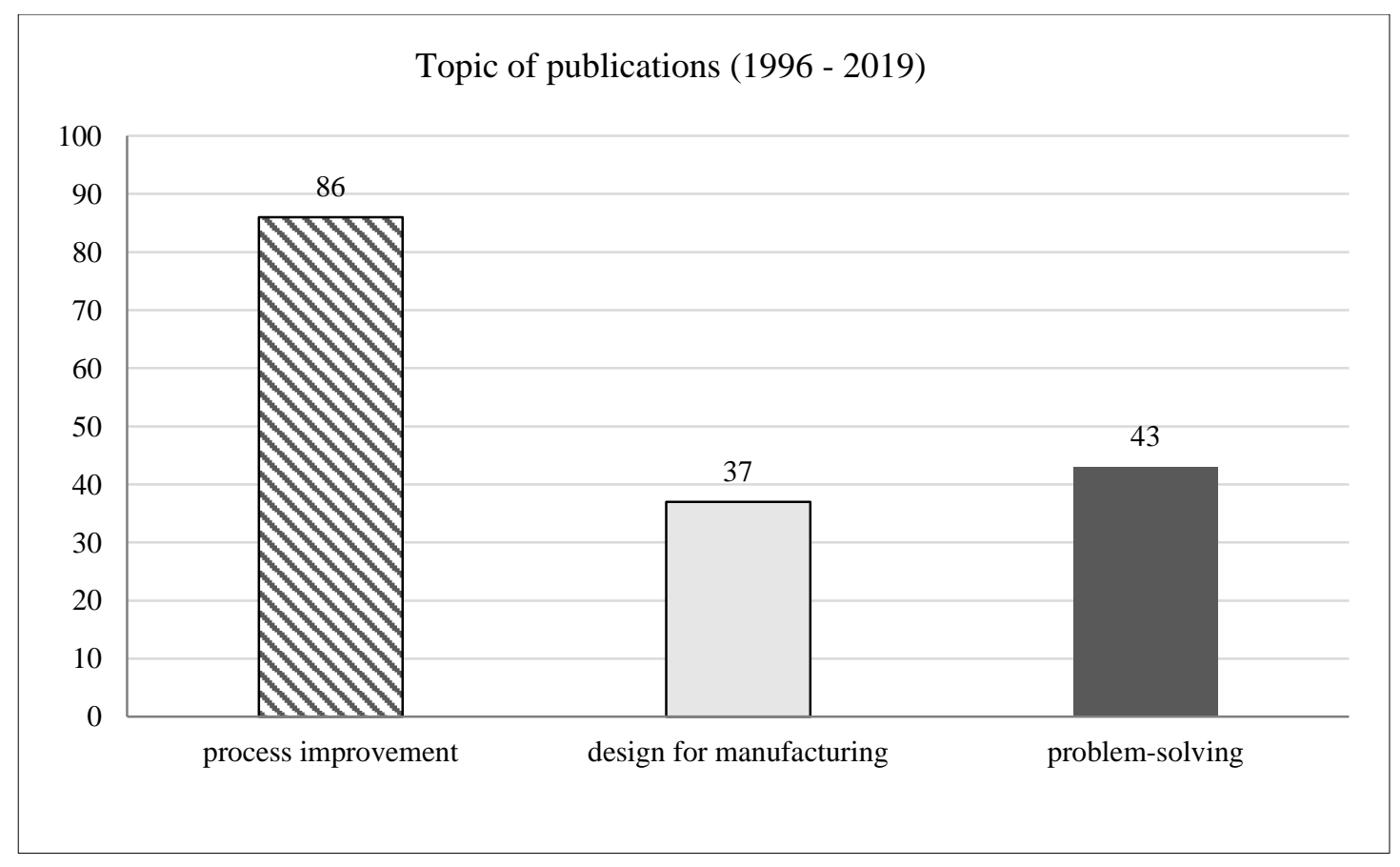

Figure 4. Groups of papers with a similar topic. 


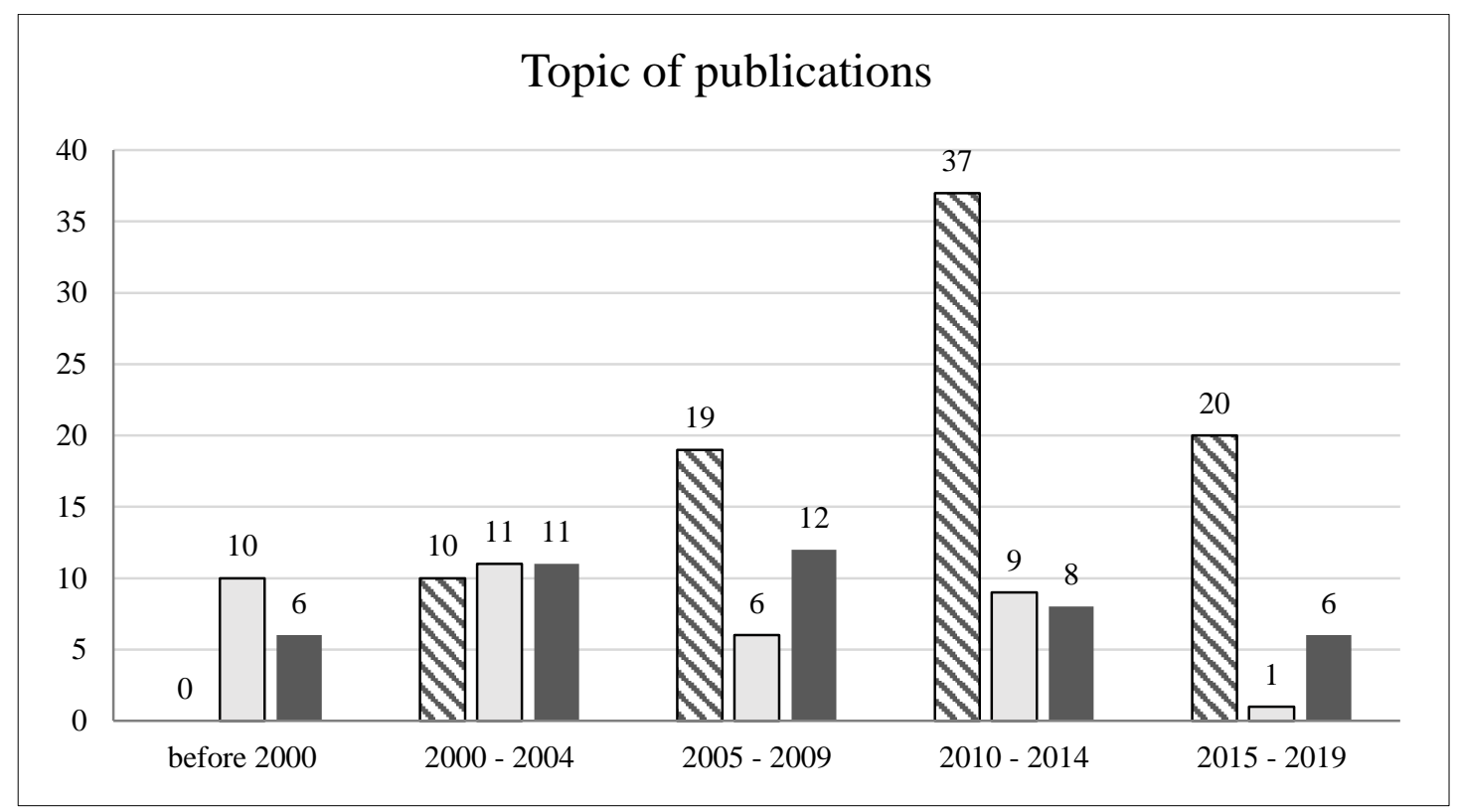

Figure 5. Publication by topic in years.

In Figure 5, there can be seen numbers of publications represented by groups with a similar topic, in periods used in this review. Firstly, TRIZ was used only for process-related activities. Attempts for use of TRIZ for process improvement appeared after the year 2000.

The result from the literature review is that the integration of TRIZ with other tools is beneficial. There are lots of publications that prove this. TRIZ was integrated with many tools and methods to achieve different goals. Lots of studies did try to combine TRIZ tools with methods for solving non-technical problems like management or strategy. Research showed that there were examples of improved processes by the combination of TRIZ and other tools. On the other hand, the complexity of TRIZ is one of the biggest weaknesses of TRIZ itself. To learn TRIZ methods takes lots of time and training is very difficult and time-consuming. Lots of publications showed only rough concepts on how TRIZ should be beneficial. Other studies are too much complicated for practical use. In different words for people who know TRIZ very well, it is simple to combine it with other tools and use it for process improvement or in other fields. But for people who never heard about TRIZ, it is very hard and time consuming to learn it and use it properly.

\section{5- Discussion}

The integration of TRIZ with tools for manufacturing or production processes is not very frequent in comparison to other tools. Most of the use of TRIZ is for innovation of products or the design of new ones. Even that TRIZ and TRIZ with other tools for process improvement should be beneficial, the difficulty of training and complexity of studies shows that TRIZ for process improvement will be used only with difficulties. If we want to use TRIZ for these purposes, a more user-friendly approach must be designed. Without tools tailored for engineers in real companies, TRIZ will hardly spread into real process improvement.

The limitation of this review is that no books were used for the research of TRIZ use for processes. There may be other examples and solutions on how to apply TRIZ for process improvement.

The next steps could be focused on the development of a new approach based on TRIZ principles, but easy to use. There were many attempts to combine TRIZ with other tools for a simpler introduction of TRIZ into companies. This approach should be changed and a new standalone method should be designed from scratch. That may help to focus on TRIZ benefits for problem-solving but also the simplicity of the tool.

\section{6- Conclusion}

TRIZ seems to be a versatile set of tools and methods for innovation. It can be combined with many different tools. This research was mainly focused on the use of TRIZ in combination with tools for process improvement. Results of research tell that TRIZ tools were used with other tools for process improvement many times. Most of the results from publications are hardly applicable in practice. The results are either abstract or too complicated for easy use. The main problem seems to be TRIZ itself, it is too complex and time-consuming to learn. If TRIZ should be used for improvement or innovation of manufacturing processes, there is a need to make new methods with a more userfriendly form and clear guidance. After that TRIZ for process improvement could be easy to spread from the academic sphere into real companies 


\section{7- Funding}

This work was supported by the Student Grant Competition of the Technical University of Liberec under the project No. SGS-2020-5027 - Research of new approaches to process improvement.

\section{8- Conflict of Interest}

The author declares that there is no conflict of interests regarding the publication of this manuscript. In addition, the ethical issues, including plagiarism, informed consent, misconduct, data fabrication and/or falsification, double publication and/or submission, and redundancies have been completely observed by the authors.

\section{9- References}

[1] Hua, Z., Yang, J., Coulibaly, S., and Zhang, B. "Integration TRIZ with Problem-Solving Tools: A Literature Review from 1995 to 2006." International Journal of Business Innovation and Research 1, (January 2006): 111-128. doi:10.1504/IJBIR.2006.011091.

[2] Coulibaly, S. "The Contribution of TRIZ Integration with Others Design Tools In the Engineering Design Process." International Journal of Innovative Research in Science, Engineering and Technology 6, no. 1, (2017): 684-693. doi:10.15680/IJIRSET.2017.0601122.

[3] Rupani, M. M., Lotfi, M. R., Nejat, A., Bakar, N. A., and Othman, F. "A Review on TRIZ Approach in Service Industry." Journal of Engineering and Applied Sciences 12, no. 6, (2017): 7815-7823. doi:10.36478/jeasci.2017.7815.7823.

[4] Lin, C. C., Lin, H.-H., and Huang, K.-C. "TRIZ Retrospect and Prospect.” 3rd International Conference on Systems and Informatics (ICSAI), Shanghai, China, (November 2016): 1072-1076. doi:10.1109/ICSAI.2016.7811110.

[5] Maia, L. C., Alves, A. C., and Leão, C. P. "How Could the TRIZ Tool Help Continuous Improvement Efforts of the Companies?” Procedia Engineering 131, (December 2015): 343-351. doi:10.1016/j.proeng.2015.12.412.

[6] Domb, E. “QFD and TIPS/TRIZ.” The TRIZ Journal, (June 1998).

[7] León-Rovira, N., and Aguayo, H. “A New Model of the Conceptual Design Process Using QFD/FA/TRIZ.” Proceedings of the 10th Annual Quality Function Deployment Symposium (1998).

[8] Domb, E. “Increase Creativity to Improve Quality.” The TRIZ Journal, (June 1998).

[9] Terninko, J. “The QFD, TRIZ and Taguchi Connection: Customer-Driven Robust Innovation.” Proceedings of the Ninth Symposium on Quality Function Deployment (1997): 441-445.

[10] Novick, D. "Variability Reduction: A Common Ground for Integration of Advanced Quality Tools and Processes." Proceedings of the 11th Symposium on Quality Function Deployment. Novi, MI, USA, (1999).

[11] Rizzo, A. R. “Tools from the Theory of Constraints.” The TRIZ Journal, (May 1997).

[12] Moura, E. C. “TOC Trees Help TRIZ.” The TRIZ Journal, (September 1999).

[13] Domb, E., and Dettmer, H. W. "Breakthrough Innovation in Conflict Resolution.” The TRIZ Journal, (May 1999).

[14] Domb, E. "Strategic TRIZ and Tactical TRIZ: Using the Technology Evolution Tools. in Izobretenia." The Journal of the Altshuller Institute, (1999).

[15] Belski, I. "Solving Problems with Method of the Ideal Result (MIR)." the Transactions from the 11th Symposium on Quality Function Deployment, Michigan, USA, (1999).

[16] Becker, K., and Domb, E. "Nlp + TRIZ = Accelerated Creativity for Product Designers." Proceedings of the 3d International Symposium on QFD, (1997).

[17] Malmqvist, J., Axelsson, R., and Johansson, M. "A Comparative Analysis of the Theory of Inventive Problem Solving and the Systematic Approach of Pahl and Beitz." Proceedings of the 1996 ASME Design Engineering Technical Conferences. (January 1996).

[18] Cavallucci, D., and Lutz, P. "Beyond TRIZ Limits.” The TRIZ Journal, (March 1998).

[19] Quartly-Watson, T. “TRIZ And Taguchi Methods At A World-Class Winery \& Vineyard.” The TRIZ Journal, (February 1999).

[20] Mann, D. “Application of Triz Tools in a Non-Technical Problem Context.” The TRIZ Journal, (August 2000).

[21] Mann, D., and Domb, E. "Using TRIZ to Overcome Business Contradictions: Profitable E-Commerce." TRIZCON2001, The Altshuller Institute. (2001).

[22] Ruchti, B., and Livotov, P. "TRIZ-Based Innovation Principles and a Process for Problem Solving in Business and Management.” the ETRIA World Conference 2001, Bath, UK, (2002): 177-186. 
[23] Mann, D. “Systematic Win-Win Problem Solving In A Business Environment.” Proceedings of TRIZCON 2002, St. Louis, USA, (2002).

[24] Apte, P. R., Shah, H., and Mann, D. “" 5W's and an H " of TRIZ Innovation.” The TRIZ Journal, (September 2001).

[25] Care, I., and Mann, D. “Using MINDMAPS with TRIZ.” The TRIZ Journal, (January 2001).

[26] Mann, D. “TRIZ Thinking Hats.” The TRIZ Journal, (March 2001).

[27] Campbell, B. "Brainstorming and TRIZ.” The TRIZ Journal, (February 2003).

[28] Hipple, J. "The Integration Of TRIZ Problem Solving Techniques With Other Problem Solving And Assessment Tools.” The TRIZ Journal, (August 2003).

[29] Apte, P. R., and Mann, D. L. "Taguchi and TRIZ: Comparisons and Opportunities.” The TRIZ Journal, (November 2001).

[30] Bridoux, D., and Mann, D. “Evolving TRIZ Using TRIZ and NLP/Neurosemantics.” Proceedings of TRIZCON 2002. (2002).

[31] Mann, D., and Stratton, R. "Physical Contradictions and Evaporating Clouds (Case Study Applications of TRIZ and the Theory of Constraints." The TRIZ Journal, (April 2000).

[32] Stratton, R., and Mann, D. "Systematic Innovation and the Underlying Principles behind TRIZ and TOC.” Journal of Materials Processing Technology 139, no. 1, (August 2003): 120-126. doi:10.1016/S0924-0136(03)00192-4.

[33] Baessler, E., Breuer, T., and Grawatsch, M. "Combining The Scenario Technique With QFD And TRIZ To A Product Innovation Methodology.” The TRIZ Journal, (January 2002).

[34] Chen, J. L., and Liu, C. C. “An Eco-Innovative Design Method by Green QFD and TRIZ Tools.” International Conference on Engineering Design ICED 03. Stockholm, Sweden, (2003): 405-406.

[35] Chen, J. L., and Liu, C.-C. "An Eco-Innovative Design Approach Incorporating the TRIZ Method without Contradiction Analysis." The Journal of Sustainable Product Design 1, no. 4, (December 2001): 263-272. doi:10.1023/A:1024621524160.

[36] De Feo, J., and Bar-El, Z. "Creating Strategic Change More Efficiently with a New Design for Six Sigma Process.” Journal of Change Management 3, no. 1, (March 2002): 60-80. doi:10.1080/714042521.

[37] Bariani, P. F., Berti, G. A., and Lucchetta, G. "A Combined DFMA and TRIZ Approach to the Simplification of Product Structure." Proceedings of the Institution of Mechanical Engineers, Part B: Journal of Engineering Manufacture 218, no. 8, (August 2004): 1023-1027. doi:10.1243/0954405041486091.

[38] Hur, W. S., Jang, J. H., Kim, D. C., and Jang, J. S. "How to Efficiently Use the TRIZ in Implementing the DFSS Projects." (2004).

[39] Averboukh, E. A. “I-TRIZ for Six Sigma Business Process Management.” The TRIZ Journal, (December 2003).

[40] Poppe, G., and Gras, B. “TRIZ in the Process Industry.” European TRIZ Association Conference (November 2001).

[41] Winkless, B., and Mann, D. "Product and Process Improvement Using TRIZ: A Case Study in Increasing Innovative Options." (January 2002).

[42] Stratton, R., and Warburton, R. D. H. "The Strategic Integration of Agile and Lean Supply.” International Journal of Production Economics 85, no. 2, (August 2003): 183-198. doi:10.1016/S0925-5273(03)00109-9.

[43] Ikovenko, S., and Bradley, J. “TRIZ as a Lean Thinking Tool.” 2004 ETRIA TRIZ Future Conference. (2004).

[44] Campbell, B. “Lean TRIZ.” The TRIZ Journal, (June 2004).

[45] Kermani, A. H. M. "Empowering Six Sigma Methodology via the Theory of Inventive Problem Solving (TRIZ)." The TRIZ Journal, (December 2003).

[46] Domb, E. "Enhance Six Sigma Creativity With TRIZ." Quality Digest, (February 2004).

[47] Retseptor, G. “40 Inventive Principles in Quality Management.” The TRIZ Journal, (March 2003).

[48] Nakamura, Y. "Combination of ARIZ92 and NM (Nakayama, Masakazu) Method for the 5-Th Level Problems." Proceedings of TRIZCON 2003. (2003).

[49] Petrali, P. "Integrating TRIZ and Other Methodologies in Product/Process Re-Engineering." The TRIZ Journal, (February 2004).

[50] Stanbrook, T. "TRIZ for Software Process Improvement.” 26th Annual International Computer Software and Applications, Oxford, UK, (2002): 466-468. doi:10.1109/CMPSAC.2002.1045046.

[51] Rea, K. C. “TRIZ and Software - 40 Principle Analogies, Part 1 and 2.” The TRIZ Journal, (September 2001). 
[52] Aggarwal, A., Kumar, S., and Sikor, T. "TOYOTrizzed: How the Celebrated TOYOTA Production System Is a TRIZ Derivative.” The TRIZ Journal, (December 2005).

[53] Robles, G. C., Negny, S., and Le Lann, J. M. "Innovation and Knowledge Management: Using the Combined Approach TRIZCBR in Process System Engineering." Computer Aided Chemical Engineering (W. Marquardt and C. Pantelides, eds.), Elsevier, (January 2006): 2237-2242. doi:10.1016/S1570-7946(06)80381-0.

[54] Duflou, J. R., and D'hondt, J. “Applying TRIZ for Systematic Manufacturing Process Innovation: The Single Point Incremental Forming Case.” Procedia Engineering 9, (January 2011): 528-537. doi:10.1016/j.proeng.2011.03.139.

[55] Jin, Y. T., San, Y. T., and Li, S. C. “TRIZ: Systematic Innovation towards Factory Operational Efficiency.” the 2008 33rd IEEE/CPMT International Electronics Manufacturing Technology Conference (IEMT), Penang, Malaysia, (November 2008). doi:10.1109/IEMT.2008.5507846.

[56] Fresner, J., and Jantschgi, D. J. "TRIZ to Improve Material Efficiency and Energy Efficiency of Industrial Production Processes." (2006).

[57] Domb, E., and Kling, T. J. "How to Reduce Cost in Product and Process Using TRIZ." (2006).

[58] Bligh, A. “The Overlap Between TRIZ and Lean.” (2006).

[59] Li, G., Tan, R., Liu, Z., and Zhang, H. "Idea Generation for Fuzzy Front End Using TRIZ and TOC.” 2006 IEEE International Conference on Management of Innovation and Technology, no. 2, Singapore, China, (June 2006): 590-594. doi:10.1109/ICMIT.2006.262287.

[60] Kumar, G. P. "Software Process Improvement -TRIZ and Six Sigma (40 Principles Usage for Level 2 Inventions)." The TRIZ Journal, (April 2005).

[61] Zhao, X. "Integrated TRIZ and Six Sigma Theories for Service/Process Innovation." the International Conference on Services Systems and Services Management, 2005., Chongquing, China, (2005): 529-532. doi:10.1109/ICSSSM.2005.1499529.

[62] Averboukh, E. A. "Six Sigma Trends: TRIZ Six Sigma for Analysis and Elimination of Root Causes” (2006).

[63] Averboukh, E. A. "Six Sigma Trends: TRIZ Six Sigma for Cost Reduction: Strategic Breakthrough Training Based Projects." The TRIZ Journal, (July 2006).

[64] Filmore, P. "A Comparison of the Problem Solving and Creativity Potential of Engineers between Using TRIZ and Lean/ Six Sigma." the The Fourth TRIZ Symposium in Japan 2008, Laforet Biwako, Moriyama, Shiga, Japan, (September 2008).

[65] Šibalija, T. V., and Majstorovic, V. D. "Six Sigma - TRIZ.” International Journal of Total Quality Management \& Excellence 37, no. 1, (2009): 376-380.

[66] Xie, J., and Li, F. "Study on Innovative Method Based on Integrated of TRIZ and DMAIC." the 2009 International Conference on Information Management, Innovation Management and Industrial Engineering, Xian, China, (2009): 351-354. doi:10.1109/ICIII.2009.92.

[67] Brad, S., Fulea, M., Emilia, B., and Mocan, B. "Systematic Integration of Innovation in Process Improvement Projects Using the Enhanced Sigma-TRIZ Algorithm and Its Effective Use by Means of a Knowledge Management Software Platform." Informatica Economica Journal 13, no. 4, (January 2009): 75-89.

[68] Chen, L.-S., Hsu, C.-C., and Chang, P.-C. "Developing a TRIZ-Kano Model for Creating Attractive Quality." the 2008 4th International Conference on Wireless Communications, Networking and Mobile Computing (WiCOM), Dalian, China, (October 2008). doi:10.1109/WiCom.2008.1854.

[69] Van Scyoc, K. "Process Safety Improvement-Quality and Target Zero." Journal of Hazardous Materials 159, no. 1, (November 2008): 42-48. doi:10.1016/j.jhazmat.2008.02.036.

[70] Hetherington, M., and Ismail, D. H. S. "Qualitative Examination of How Agility and Agile Manufacturing Fit with Traditional Strategy and the TRIZ Framework.” IET International Conference on Agile Manufacturing (ICAM 2007), Durham, UK, (2007): 212-220. doi:10.1049/cp:20070029.

[71] Movarrei, R., and Vessal, S. R. "Theory of Inventive Problem Solving (TRIZ) Applied in Supply Chain Management of Petrochemical Projects." the 2007 IEEE International Conference on Industrial Engineering and Engineering Management, Singapore, (December 2007): 1624-1628. doi:10.1109/IEEM.2007.4419467.

[72] Rau, H., and Fang, Y.-T. "Conflict Resolution of Product Package Design for Logistics Using the TRIZ Method." the 2009 International Conference on Machine Learning and Cybernetics (ICMLC), Baoding, China, (July 2009): 2891-2896. doi: 10.1109/ICMLC.2009.5212618.

[73] Su, C.-T., and Lin, C.-S. “A Case Study on the Application of Fuzzy QFD in TRIZ for Service Quality Improvement.” Quality \& Quantity 42, no. 5, (October 2008): 563-578. doi:10.1007/s11135-006-9058-y.

[74] Wang, C.-S., Yu, C.-R., and Chang, T.-R. “Integrated QFD, TRIZ and FMEA for Product Development Process.” (2005). 
[75] Shahbazpour, M., and Seidel, R. "Strategic Manufacturing System and Process Innovation through Elimination of Trade-Offs." International Journal of Computer Integrated Manufacturing 20, no. 5, (July 2007): 413-422. doi:10.1080/09511920601160106.

[76] Prim, M. F., and Trabasso, L. G. "Theory of Inventive Problem Solving Applied To Business Process Management Projects (BPM-TRIZ).” Proceedings of COBEM 2005: 18th International Congress of Mechanical Engineering. (2005).

[77] Ru, H., and Ru, H. “Applying TRIZ in Process Improvement.” The TRIZ Journal, (May 2006).

[78] Smith, H. "P-TRIZ in the History of Business Process - Part 3 in a Series on P-TRIZ." www.bptrends.com, (April 2006).

[79] Souchkov, V. "Breakthrough Thinking with TRIZ for Business and Management: An Overview.” (April 2007).

[80] Sui, J., Hu, Y., and Yu, J. "Research on the Strategy and Implementation in Stages of Organizational Learning Based on TRIZ Theory." 2009 16th International Conference on Industrial Engineering and Engineering Management, Beijing, China, (October 2009): 665-669. doi:10.1109/ICIEEM.2009.5344506.

[81] Hipple, J. "The Integration of TRIZ with Other Ideation Tools and Processes as Well as with Psychological Assessment Tools." Creativity and Innovation Management 14, no. 1, (March 2005): 22-33. doi:10.1111/j.1476-8691.2005.00322.x.

[82] Hipple, J. "The Integration and Strategic Use of TRIZ with the Basic CPS (Creative Problem Solving) Process." The TRIZ Journal, (March 2005).

[83] Frenklach, G. “Multi-Level Problem Solving.” The TRIZ Journal, (January 2007).

[84] Khomenko, N., and Ashtiani, M. "Classical TRIZ and OTSM as a Scientific Theoretical Background for Non- Typical Problem Solving Instruments." (2007).

[85] Cavallucci, D., and Khomenko, N. "From TRIZ to OTSM-TRIZ: Addressing Complexity Challenges in Inventive Design." International Journal of Product Development 4, no. 1/2, (2007) doi:10.1504/IJPD.2007.011530.

[86] Bolton, J. D. "Utilization of TRIZ with DFMA to Maximize Value." SAVE International - 47th Annual Conference: Achieving Value Through Innovation (2007): 22-32.

[87] Dietz, T. P., and Mistree, F. "Integrated Pahl and Beitz and the Theory of Inventive Problem Solving for the Conceptual Design of Multi-Domain Systems." the ASME 2009 International Design Engineering Technical Conferences and Computers and Information in Engineering Conference, San Diego, California, USA, (January 2009): 189-202. doi:10.1115/DETC200987311.

[88] Chan, C. C. S., Yu, K.-M., and Yung, K. L. "Green Manufacturing Using Integrated Decision Tools. 2010 IEEE International Conference on Industrial Engineering and Engineering Management, Macao, China, (December 2010): $2287-2291$. doi:10.1109/IEEM.2010.5674169.

[89] Martin, A. "TRIZ, Theory of Constraints and Lean.” (2010).

[90] Anosike, A. I., and Lim, M. K. "Integrating Lean, Theory of Constraints and TRIZ for Process Innovation." Short Research Papers on Knowledge, Innovation and Enterprise, (2013): 64-74.

[91] Anosike, A. I., and Lim, M. K. “A Synergistic Approach to Process Innovation.” International Journal of Knowledge, Innovation and Entrepreneurship 2, no. 1, (2014): 33-54.

[92] Navas, H. V. G., and Machado, V. A. C. ““The Lifeline” of Technical Systems in a TRIZ-LEAN Environment.” Proceedings of TRIZ Future 2011 (2011).

[93] Wang, C.-N., and Hsiung, W.-M. “Application of TRIZ to Improve the Layout for a Screw Packaging Factory.” 2011 IEEE 18th International Conference on Industrial Engineering and Engineering Management, Changchun, China, (September 2011): 62-66. doi:10.1109/ICIEEM.2011.6035106.

[94] Bashikite, V., and Karaulova, T. "Integration of Green Thinking into Lean Fundamentals by Theory of Inventive Problems Solving Tools." Annals of DAAAM for 2012 \& Proceedings of the 23rd International DAAAM Symposium 23, no. 1, (2012): 345-350.

[95] Li, L., Li, D., and Yang, Y. "The Design and Application of Synergetic Innovation System for Manufacturing Enterprise Based on TRIZ." 2011 International Conference on Information Management, Innovation Management and Industrial Engineering (ICIII), Shenzhen, China, (November 2011): 74-77. doi:10.1109/ICIII.2011.166.

[96] Lanke, A., and Ghodrati, B. "Reducing Defects and Achieving Business Profitability Using Innovative and Lean Thinking." 2013 IEEE International Conference on Industrial Engineering and Engineering Management (IEEM), Bangkok, Thailand, (December 2013): 1026-1030. doi:10.1109/IEEM.2013.6962566.

[97] Moreira, D. “Component Misplacement Prevention on the ICOS Tape \& Reel Process Using TRIZ \& Lean.” IPC APEX EXPO Proceedings (2012). 
[98] Muruganantham, V. R., Krishnan, P. N., and Arun, K. K. "Integrated Application of TRIZ with Lean in the Manufacturing Process in a Machine Shop for the Productivity Improvement." International Journal of Productivity and Quality Management 13, no. 4, (2014): 414-429. doi:10.1504/IJPQM.2014.062220.

[99] Hsia, T. C., Chen, S. C., Tsai, R. K., and Huang, S. C. "Using Systematic Innovation Process (TRIZ Method) to Improve the Manufacturing Technology of Platelet Agitators.” Flexible Automation and Intelligent Manufacturing (FAIM2011), no. 44, (2011).

[100] Sheu, D. D., and Hou, C. T. "TRIZ-Based Problem Solving for Process-Machine Improvements: Slit-Valve Innovative Redesign.” 41st International Conference on Computers \& Industrial Engineering (2011): 1036-1044.

[101] Sheu, D. D., and Hou, C. T. "TRIZ-Based Trimming for Process-Machine Improvements: Slit-Valve Innovative Redesign." Computers \& Industrial Engineering 66, no. 3, (November 2013): 555-566. doi:10.1016/j.cie.2013.02.006.

[102] Hsia, T.-C., and Huang, S.-C. "Using the Theory of Inventive Problem-Solving (TRIZ) to Implement Safety Improvements in Foundry Engineering Pouring Procedures.” 2011 International Conference on Management and Service Science (MASS 2011), Wuhan, China, (August 2011). doi:10.1109/ICMSS.2011.5999352.

[103] Navas, H. V. G., and Machado, V. A. C. "Systematic Innovation in a Lean Management Environment." 2013 Industrial and Systems Engineering Research Conference, San Juan, Puerto Rico, (2013). doi:10.13140/RG.2.1.2046.4083.

[104] Sousa, N. J. P. E., Navas, H. V. G., and Machado, V. A. C. "Application of Lean and TRIZ Methodologies in the Maintenance Service of a Food Company.” ICSI 2014 - The 5th International Conference on Systematic Innovation, At San Jose, California, USA, (2014). doi:10.13140/RG.2.1.1506.1842.

[105] Thurnes, C., Zeihsel, F., and Hallfell, F. "TRIZ for Waste Elimination on a "Lean Production" Environment." Proceedings of TRIZfest 2014 (2014): 284-292.

[106] Thurnes, C. "Lean-Operators for the 40 Inventive Principles.” (2014).

[107] Muruganantham, V. R., Krishnan, P. N., and Arun, K. K. "Performance Improvement and Cost Minimisation for Manufacturing Components in a Fabrication Plant by the Application of Lean with TRIZ Principles." International Journal of Productivity and Quality Management 12, no. 4, (2013): 449-465. doi:10.1504/IJPQM.2013.056737.

[108] Cabrera, B. R., and Li, G. J. “A Lean-TRIZ Approach for Improving the Perfomance of Construction Projects.” XXII Conference of Lean Construction, no. 22, Oslo, Norway, (2014): 883-894.

[109] Navas, H. V. G., and Machado, V. A. C. "Systematic Innovation for Lean Supply Chain Management.” ICPR 22 - 22nd International Conference on Production Research, no. 22, Iguassu Falls, Brazil, (2013). doi:10.13140/RG.2.1.3533.9608.

[110] Moussa, B., Zahra, F., Benmoussa, R., Dubois, S., De Guio, R., Gartiser, N., and Rasovska, I. "How Can TRIZ Contributes to Solve the Problems of Green Logistics?” International Conference on Green Supply Chain: GSC', (January 2014).

[111] Dewi, S. R., Setiawan, B., and Susatyo Nugroho, W. P. “5S Program to Reduce Change-over Time on Forming Department (Case Study on CV Piranti Works Temanggung).” IOP Conference Series: Materials Science and Engineering 46, (June 2013) doi:10.1088/1757-899X/46/1/012040.

[112] Kumaresan, K. S., and Saman, M. Z. M. "Integration of SMED and TRIZ in Improving Productivity at Semiconductor Industry." Jurnal Mekanikal 33, no. 2, (2011): 40-55.

[113] Brad, S. "Sigma-TRIZ: Algorithm for Systematic Integration of Innovation within Six Sigma Process Improvement Methodologies." Quality Management and Six Sigma, (August 2010): 89-108.

[114] Soti, A., Shankar, R., and Kaushal, O. P. "Six Sigma with Innovation Tool Kit of TRIZ.” International Journal of Business Innovation and Research 6, no. 2, (2012): 220-237. doi:10.1504/IJBIR.2012.045638.

[115] Zhao, X., and Zhao, Y. "Optimizing Six Sigma Processes to Satisfy Customers by TRIZ Innovation Methodology." Proceedings of 2013 4th International Asia Conference on Industrial Engineering and Management Innovation (IEMI2013), Berlin, Heidelberg, (2014): 753-759. doi:10.1007/978-3-642-40060-5_72.

[116] Wang, F.-K., and Chen, K.-S. "Applying Lean Six Sigma and TRIZ Methodology in Banking Services.” Total Quality Management \& Business Excellence 21, no. 3, (March 2010): 301-315. doi:10.1080/14783360903553248.

[117] Annamalai, N., Kamaruddin, S., Azid, I. A., and Yeoh, T. S. "Clustered Model TRIZ and Application in Industries." International Journal of Innovation, Management and Technology 5, no. 5, (2014): 368-373. doi:10.7763/IJIMT.2014.V5.542.

[118] Yang, C., Huang, R. H., and Wei, W. L. "Using modified TRIZ approach for quality improvement." Science Journal of Business and Management 1, no. 1, (2013): 14-18.

[119] Guo, Y., Sun, M.-G., and Xu, M. "Using TRIZ to a Quality Improvement - Case Study of Foxbro in Shanghai." International Journal of Business and Economic Development 2, no. 2, (2014): 61-69. 
[120] Wirawan, C., and Ayu, A. P. "TRIZ Based Approach to Improve Public Bus Service Quality.” 2014 IEEE International Conference on Industrial Engineering and Engineering Management (IEEM), Selangor Darul Ehsan, Malaysia, (December 2014): 793-797. doi:10.1109/IEEM.2014.7058747.

[121] Kim, S., and Yoon, B. "Developing a Process of Concept Generation for New Product-Service Systems: A QFD and TRIZBased Approach.” Service Business 6, no. 3, (September 2012) 323-348. doi:10.1007/s11628-012-0138-x.

[122] Regazzoni, D., Pezzotta, G., Persico, S., Cavalieri, S., and Rizzi, C. "Integration of TRIZ Problem Solving Tools in a Product-Service Engineering Process.” The Philosopher's Stone for Sustainability, Berlin, Heidelberg, (2013): 399-404. doi:10.1007/978-3-642-32847-3_67.

[123] Cascini, G. “TRIZ-Based Anticipatory Design of Future Products and Processes.” Journal of Integrated Design \& Process Science 16, no. 3, (2012): 29-63. doi:10.3233/jid-2012-0005.

[124] Wang, C.-S., and Chang, T.-R. "Systematic Strategies in Design Process for Innovative Product Development." 2010 IEEE 17Th International Conference on Industrial Engineering and Engineering Management, Xiamen, China, (October 2010): 898-902. doi:10.1109/ICIEEM.2010.5646480.

[125] Minglang, Y., Jianghua, H., and Huang, L. "Research of Product Innovative Models Based on QFD, TRIZ and DOE." 2010 IEEE 11th International Conference on Computer-Aided Industrial Design Conceptual Design 1, no. 1, Yiwu, China, (November 2010): 325-328. doi:10.1109/CAIDCD.2010.5681343.

[126] Tseng, C. C., Torng, C. C., and Lin, S. C. "Prioritization of Product Design Tasks Using QFD, TRIZ and DSM.” 2010 IEEE 17Th International Conference on Industrial Engineering and Engineering Management, Xiamen, China, (October 2010): 871-875. doi:10.1109/ICIEEM.2010.5646486.

[127] Zheng, H., Zhang, H., and Zhang, F. "An Innovative Design of Energy-Saving Products Based on QFD/TRIZ/DEA Integration.” 2010 IEEE 17Th International Conference on Industrial Engineering and Engineering Management, Xiamen, China, (October 2010): 831-834. doi:10.1109/ICIEEM.2010.5646494.

[128] Hu, C.-M., and Yeh, C.-H. "The Synergy of QFD and TRIZ Design Practice - A Case Study for Medical Care Bed.” 2011 International Conference on Modelling, Identification and Control, Shanghai, (June 2011): 523-531. doi:10.1109/ICMIC.2011.5973760.

[129] Jou, Y.-T., Lin, W.-T., Lee, W.-C., and Yeh, T.-M. "Integrating the TRIZ and Taguchi's Method in the Optimization of Processes Parameters for SMT." Advances in Materials Science and Engineering 2013, (2013): 1-10. doi:10.1155/2013/830891.

[130] Lee, L. J. H., and Leu, J.-D. "Using Value Engineering and TRIZ for Better Business Process Management." Industrial Engineering (CIE-40), Awaji City, Japan, (July 2010). doi:10.1109/ICCIE.2010.5668230.

[131] Jiannan, Z., and Dongmei, Y. “A TRIZ-Based Process Model for Technology Evolutionary Potential Forecast.” 2010 IEEE 11th International Conference on Computer-Aided Industrial Design \& Conceptual Design 1, Yiwu, China, (2010): 458-462. doi:10.1109/CAIDCD.2010.5681309.

[132] Lebepe, B. A., and Emwanu, B. "Comparing Theory of Constraints (TOC) with TRIZ in Solving a Production Problem in South Africa - A Case Study.” SAIIE25 Proceedings (2013).

[133] Hass, J., Rensch, C., Salvamoser, R., Münzberg, C., Lindemann, U., and Mayer, O. "Experimental Proof of the Creative Value of TRIZ." TRIZfest 2014, (2014): 144-152

[134] Jirman, P., and Masin, I. “TRIZ Tools Evaluation From the Production Plant Viewpoint.” TRIZfest 2014, (2014): $306-331$.

[135] Ioi, T., Hata, S., Nagami, S., and Okuhara, H. "Project Management Incorporating Dynamic Simulation \& TRIZ.” Journal on Innovation and Sustainability 3, no. 2, (August 2012) doi:10.24212/2179-3565.2012v3i2p35-44.

[136] Petrović, M., Miljković, Z., and Babić, B. "Integration of Process Planning, Scheduling, and Mobile Robot Navigation Based on TRIZ and Multi-Agent Methodology.” FME Transactions 41, no. 2, (June 2013): 97-106.

[137] Ferrer, J. B., Negny, S., Robles, G. C., and Le Lann, J. M. "Eco-Innovative Design Method for Process Engineering." Computers \& Chemical Engineering 45, (October 2012): 137-151. doi:10.1016/j.compchemeng.2012.06.020.

[138] Azlan, A. D., Ariz, B., and Yusof, K. M. "Perceptions on TRIZ by Current TRIZ Experts in the Industry: A Review in Malaysia.” International Conference on Teaching and Learning in Computing and Engineering, (2014): 325-331.

[139] Brad, S., Mocan, B., Brad, E., and Fulea, M. "Leading Innovation to Improve Complex Process Performances by Systematic Problem Analysis with TRIZ.” Procedia Engineering 131, (January 2015): 1121-1129. doi:10.1016/j.proeng.2015.12.430.

[140] Li, M., Ming, X., Zheng, M., He, L., and Xu, Z. "An Integrated TRIZ Approach for Technological Process and Product Innovation.” Proceedings of the Institution of Mechanical Engineers, Part B: Journal of Engineering Manufacture 231, no. 6, (May 2017): 1062-1077. doi:10.1177/0954405415583885. 
[141] Toivonen, T. “Continuous Innovation - Combining Toyota Kata and TRIZ for Sustained Innovation.” Procedia Engineering 131, (January 2015): 963-974. doi:10.1016/j.proeng.2015.12.408.

[142] Arcidiacono, G., and Bucciarelli, L. "TRIZ: Engineering Methodologies to Improve the Process Reliability: TRIZ in Process Reliability." Quality and Reliability Engineering International 32, no. 7, (November 2016): 2537-2547. doi:10.1002/qre.1955.

[143] Alves, J. F., Navas, H. V. G., and Nunes, I. L. "Application of TRIZ Methodology for Ergonomic Problem Solving in a Continuous Improvement Environment." Advances in Safety Management and Human Factors, Cham, (2016): 473-485. doi:10.1007/978-3-319-41929-9_43.

[144] de J. Pacheco, D. A., Caten, C. S., Navas, H. V. G., Jung, C. F., Machado, V. A. C., and Lopes, G. H. N. "Systematic EcoInnovation in Lean PSS Environment: An Integrated Model." Procedia CIRP 47, (January 2016): 466-471. doi:10.1016/j.procir.2016.03.211.

[145] Ghani, J. A., Natasha, A. R., Hassan, C. H. C., and Syarif, J. "TRIZ Approach for Machining Process Innovation in Cryogenic Environment." International Journal of Materials and Product Technology 53, no. 3/4, (2016): 286. doi:10.1504/IJMPT.2016.079200.

[146] Karaulova, T., and Bashkite, V. "Decision-Making Framework for Used Industrial Equipment.” Engineering Economics 27, no. 1, (March 2016): 23-31. doi:10.5755/j01.ee.27.1.8618.

[147] Hsieh, H.-N., Chen, J.-F., and Do, Q. H. "Applying TRIZ and Fuzzy AHP Based on Lean Production to Develop an Innovative Design of a New Shape for Machine Tools." Information 6, no. 1, (March 2015): 89-110. doi:10.3390/info6010089.

[148] Toivonen, T., and Siitonen, J. "Value Stream Analysis for Complex Processes and Systems." Procedia CIRP 39, (January 2016): 9-15. doi:10.1016/j.procir.2016.01.035.

[149] Su, C.-T., and Su, F.-M. "Yield Improvement in Color Filter Manufacturing Using Taguchi Methods and TRIZ's SubstanceField Analysis." IEEE Transactions on Components, Packaging and Manufacturing Technology 8, no. 12, (December 2018): 2198-2212. doi:10.1109/TCPMT.2018.2846692.

[150] Livotov, P., Chandra Sekaran, A. P., Law, R., Mas'udah, and Reay, D. "Systematic Innovation in Process Engineering: Linking TRIZ and Process Intensification.” Advances in Systematic Creativity: Creating and Managing Innovations (L. Chechurin and M. Collan, eds.), Springer International Publishing, Cham, (2019): 27-44.

[151] Pokhrel, C., Cruz, C., Ramirez, Y., and Kraslawski, A. "Adaptation of TRIZ Contradiction Matrix for Solving Problems in Process Engineering." Chemical Engineering Research and Design 103, (November 2015): 3-10. doi:10.1016/j.cherd.2015.10.012.

[152] Jiang, J.-C., and Nguyen, T.-A.-T. "Process Improvement by Application of Lean Six Sigma and TRIZ Methodology - Case Study in Coffee Company." International Journal of Application or Innovation in Engineering \& Management 4, no. 3, (March 2015): 208-219.

[153] Lin, C.-H., Lin, W.-T., Jou, Y.-T., Wu, W.-T., and Yan, Z.-H. "A Study of Process Optimization for Roasting Taiwanese Coffees by Applying Six Sigma." 2016 International Conference on Fuzzy Theory and Its Applications (iFuzzy), Taichung, Taiwan, (November 2016). doi:10.1109/iFUZZY.2016.8004963.

[154] Brad, S., and Brad, E. "Enhancing SWOT Analysis with TRIZ-Based Tools to Integrate Systematic Innovation in Early Task Design.” Procedia Engineering 131, (January 2015): 616-625. doi:10.1016/j.proeng.2015.12.455.

[155] Harlim, J., and Belski, I. "On the Effectiveness of TRIZ Tools for Problem Finding." Procedia Engineering 131, (January 2015): 892-898. doi:10.1016/j.proeng.2015.12.400.

[156] Karnjanasomwong, J., and Thawesaengskulthai, N. "TRIZ-PUGH Model, New Approach for Creative Problem Solving and Decision Making.” 2015 IEEE International Conference on Industrial Engineering and Engineering Management (IEEM), Singapore, Singapore, (December 2015): 1757-1761.doi:10.1109/IEEM.2015.7385949.

[157] Lee, L. J.-H., Leu, J.-D., and Huang, Y.-W. "A Value Engineering Based Method of Configuring ICT-Based Customer Service Centers." 2015 2nd International Conference on Information Science and Control Engineering (ICISCE), Shanghai, China, (April 2015): 86-91. doi:10.1109/ICISCE.2015.28.

[158] Lee, C.-H., Chen, C.-H., and Trappey, A. J. C. "Applying Theory of Inventive Problem Solving to Develop Product-Service System." 2017 IEEE 21st International Conference on Computer Supported Cooperative Work in Design (CSCWD), Wellington, New Zealand, (April 2017): 198-202. doi:10.1109/CSCWD.2017.8066694.

[159] Zulhasni, A. R., Nooh, A. B., Sarimah, M., and Yeoh, T. S. "TRIZ Business Improvement and Innovation Framework for Malaysian Small and Medium Enterprise." Applied Mechanics and Materials 735, (February 2015): $349-353$. doi:10.4028/www.scientific.net/AMM.735.349.

[160] Chrząszcz, J. "From Problem to Objective - Complementing TRIZ with NLP." Proceedings of the MATRIZ TRIZfest 2017 International Conference. (2017). 
[161] Swee, N. S. L., Toh, G. G., Yip, M. W., Keong, C. S., and Tai, S. C. “Applying Triz for Production Quality Improvement.” MATEC Web of Conferences 95, no. 10009, (2017). doi:/10.1051/matecconf/20179510009.

[162] Shealy, T., Hu, M., and Gero, J. "Patterns of Cortical Activation When Using Concept Generation Techniques of Brainstorming, Morphological Analysis, and TRIZ.” ASME 2018 International Design Engineering Technical Conferences and Computers and Information in Engineering Conference, Quebec City, Quebec, Canada, (August 2018). doi:10.1115/DETC2018-86272.

[163] Navas, H. V. G., Tenera, A. M. B. R., and Machado, V. A. C. "Integrating TRIZ in Project Management Processes: An ARIZ Contribution.” Procedia Engineering 131, (2015): 224-231. doi:10.1016/j.proeng.2015.12.381. 